Research, part of a Special Feature on Nudging Evolution? Critical Exploration of the Potential and Limitations of the Concept of Institutional Fit for the Study and Adaptive Management of Social-Ecological Systems

\title{
Institutional Fit and River Basin Governance: a New Approach Using Multiple Composite Measures
}

\author{
$\underline{\text { Louis Lebel }}^{1}$, Elena Nikitina $^{2}$, Claudia Pahl-Wostl $^{3}{\text { and } \text { Christian Knieper }^{3}}^{3}$
}

\begin{abstract}
The notion that effective environmental governance depends in part on achieving a reasonable fit between institutional arrangements and the features of ecosystems and their interconnections with users has been central to much thinking about social-ecological systems for more than a decade. Based on expert consultations this study proposes a set of six dimensions of fit for water governance regimes and then empirically explores variation in measures of these in 28 case studies of national parts of river basins in Europe, Asia, Latin America, and Africa drawing on a database compiled by the Twin2Go project. The six measures capture different but potentially important dimensions of fit: allocation, integration, conservation, basinization, participation, and adaptation. Based on combinations of responses to a standard questionnaire filled in by groups of experts in each basin we derived quantitative measures for each indicator. Substantial variation in these measures of fit was apparent among basins in developing and developed countries. Geographical location is not a barrier to high institutional fit; but within basins different measures of fit often diverge. This suggests it is difficult, but not impossible, to simultaneously achieve a high fit against multiple challenging conditions. Comparing multidimensional fit profiles give a sense of how well water governance regimes are equipped for dealing with a range of natural resource and use-related conditions and suggests areas for priority intervention. The findings of this study thus confirm and help explain previous work that has concluded that context is important for understanding the variable consequences of institutional reform on water governance practices as well as on social and environmental outcomes.
\end{abstract}

Key Words: comparative analysis; indicators; institutional fit; measuring fit; river basin management; water governance

\section{INTRODUCTION}

The notion that effective environmental governance depends in part on achieving a reasonable fit between institutional arrangements on the one hand, and ecosystem and social processes on the other, has been central to much thinking about social-ecological systems (Ostrom 1990, 2010, Young et al. 1999, Young 2002, Galaz et al. 2008). Institutions, it is argued, should take into account the spatial and temporal scales of key ecosystem processes (Cash et al. 2006, Folke et al. 2007); their scope should also reflect important social-ecological linkages, for example, those influencing resilience and adaptive capacities (Folke et al. 2005, Lebel et al. 2006).

Exactly which dimensions of institutional fit are important in particular circumstances and how stakeholders come to agree on these dimensions has turned out to be a challenging research and policy puzzle. Although there are no panaceas (Ostrom et al. 2007), diagnostic analyses and learning from adaptive approaches as well as explicit efforts to measure fit have started to provide insights. The first has been the growing recognition that governance systems, including, in addition to rules and norms, relationships of power, authority, and legitimacy, are themselves complex adaptive systems with nonlinear dynamics that can include periods of stasis and incremental modification as well as more abrupt and transformational change (Young 2010). The second related insight is that cross- scale interactions, disturbance, crises, and surprises can influence the evolution of fit (Cash et al. 2006, Folke et al. 2007). The third has been that fit can be meaningfully measured to assess gaps as well as to compare alternative institutional arrangements (Galaz et al. 2008, Ekstrom and Young 2009).

Scholarship on the transfer of best practices in water management can be interpreted as being about identifying solutions for a good fit (Franks et al. 2008). A core rationale for river basin management, for instance, is to address issues of spatial misfit, such as when political boundaries divide upstream and downstream uses (Moss 2004, Lebel et al. 2005). A few studies have addressed issues of institutional fit arising with the introduction of Integrated Water Resources Management (IWRM) in river basins. Chereni's (2007) study of the Mazowe catchment in Zimbabwe illustrated a few ways in which poor fits can arise, for example, as a consequence of lack of correspondence between land and water management institutions at the local level, or because weak institutions can be ignored by powerful actors leading to poorly defined roles and relationships. A study by Lankford and colleagues (2004) in the Great Ruaha River basin in southwest Tanzania documented how entrenched views and insufficient attention to deliberation and policy uptake by scientists meant that sound and important information on causes of water scarcity could

${ }^{1}$ Chiang Mai University, Thailand, ${ }^{2}$ Ecopolicy, Moscow, Russian Federation, ${ }^{3}$ Institute of Environmental Systems Research, University of Osnabrueck, Germany 
be ignored. Myint's (2003) comparative study of the Mekong and Rhine argued that fit to human system or institutional setting can be even more important than fit to the biogeophysical system.

A study of watershed councils in Oregon, USA, suggests the main obstacles to more adaptive management were in fitting in with existing institutions, such as state guidelines and practices of county authorities, as well as concerns and needs of private landowners, rather than issues related to characteristics of the aquatic resources themselves (Habron 2003). An analysis at a major larger scale of the EU Water Framework Directive (WFD) in Germany drew a similar conclusion on the importance of fit with existing institutions (Moss 2004): partnership and cross-sector orientation of the WFD did not fit well with state-centered and regulatory traditions in Germany. Another study in Australia dealing with water quality issues in the Great Barrier Reef region underlined that collaborative partnerships should not be overly fixed, but allowed to develop to fit the purpose and management problem (Lane and Robinson 2009). Participation of and coordination among multiple stakeholders are important dimensions of institutional fit.

Concerns with impacts of climate change on river basin management have triggered several reviews and comparative studies that, although they do not always explicitly refer to notions of fit, are useful to understanding. The skill with which a governance system deals with variability and uncertainty over time appears crucial to building adaptive capacity (Huntjens et al. 2010, Krysanova et al. 2010). Social learning processes are important for improving or maintaining performance (Pahl-Wostl et al. 2007, Huitema et al. 2010, Lebel et al. 2010). Polycentric systems that create multiple centers of authority but still maintain adequate vertical and horizontal coordination improve performance across a range of socioeconomic contexts (Pahl-Wostl et al. 2012). These studies also identify important barriers to more adaptive forms of governance, which would make dealing with climate variability and change easier, for example, with respect to cooperation and information sharing (Isendahl et al. 2009, Huntjens et al. 2010). These observations suggest value in a more detailed exploration of the relationships between specific water governance regime features in river basins and problem structures including key elements of social and ecological context.

In this paper we extend this early work comparing water governance regimes using the concept of fit. Our aim was to develop an approach for measuring fit that could inform diagnostic analysis (Ostrom et al. 2007, Young 2011). First, a set of fit dimensions was identified based on views of experts on best practices and their transfer. Quantitative indicators of fit were then defined as the difference between measures of institutional capacity of a water governance regime and the degree to which social-ecological conditions, or context, were challenging for that aspect of governance. These indicators, in turn, were derived by aggregating across responses from sets of questions providing robust measures. In this conceptualization a good fit corresponds to high capacity relative to challenging conditions, and vice versa. Second, we analyzed how these measures of fit varied geographically and with each other. Finally, we considered how measures of fit might inform policy and practice.

\section{METHODS}

\section{Study basins}

Twenty-eight case studies of the national parts of river basins in Europe, Asia, Latin America, and Africa that previously were a part of EU Basin Twinning Projects were recruited into the Twin2Go project (D'Haeyer et al. 2011). These are listed in Table A1.1. One case study in the original dataset, the Paute in Ecuador, was excluded from the analysis in this paper because of several missing variables. In a few instances there were separate case studies in different countries from the same transboundary river basin. Twinning projects involved pairing of a basin in Europe with one in a developing country: this is why there were no cases from North America or Australia.

A mixed methods approach was used in this study (Bryman 2006). Qualitative analysis drove the initial identification of fit dimensions that were then modeled quantitatively by creating aggregate indicators from a questionnaire. Statistical methods were then used to explore variation in the derived fit measures among basins. Finally, qualitative analysis was used again to help interpret and illustrate findings.

\section{Experts' views on best and better practices}

The views of experts on what constitutes best practices in water governance were obtained from written responses to a case study questionnaire form filled in by Twin2Go partners and then reviewed, extended, and added to in four regional best practice workshops (Russia/Newly Independent States, Asia, Africa, and Latin America). Altogether 43 individual best practice descriptions were used from 26 of the 28 basins. Altogether 71 individuals were involved in preparing these case study descriptions with representatives from government (27), academia (26), nongovernmental organizations (11), and the private sector (7). Government agencies were involved as implementers of best practices in about two-thirds of the cases described. In this study a best practice is defined as "a technique, management method, process, activity, incentive, or reward that is believed to be more effective at delivering a particular outcome than any other when applied to a particular condition or circumstance" (Nikitina et al. 2011:73). Some individual experts preferred the notion of 'better practice,' because it captures the idea of progressive improvement, and others 'good practice.' We accepted all formulations. Views on what constituted best practices in particular situations were 
Table 1. Measures of fit for water governance regimes and the number of variables used in their derivation.

\begin{tabular}{llcc}
\hline \hline $\begin{array}{l}\text { Fit } \\
\text { measure }\end{array}$ & Explanation & Condition variables & Institutional variables \\
\hline $\begin{array}{l}\text { F1 Allocation } \\
\text { F2 Integration }\end{array}$ & $\begin{array}{l}\text { Capacities to manage water shortages relative to level of water scarcity } \\
\text { Capacities to integrate/coordinate water uses relative to the complexity of } \\
\text { uses }\end{array}$ & 7 & 7 \\
F3 Conservation & $\begin{array}{l}\text { Capacities to manage water pollution and aquatic ecosystems relative to } \\
\text { the level of threats to water quality and ecosystem integrity }\end{array}$ & 6 & 13 \\
F4 Basinization & $\begin{array}{l}\text { Capacities to manage at basin level relative to the level of difficulty in } \\
\text { controlling flows at basin level }\end{array}$ & 7 & 10 \\
F5 Participation & $\begin{array}{l}\text { Capacities to engage stakeholders relative to the diversity of interests } \\
\text { Capacities to manage risks and change relative to the level of variability } \\
\text { F6 Adaptation }\end{array}$ & 2 & 2 \\
\hline
\end{tabular}

interpreted as perspectives on what constitutes a good fit (c.f. Folke et al. 2007).

Coding of text was done using NVIVO software and then used for interpretive analysis. All formal coding was done by one of the authors (LL). Interpretive analysis of the coded texts was done by two authors (LL and EN). In the first pass through text, questions in the inventory questionnaire were used to break-up text into similar sections, for example, about reasons, or opportunities and drivers. In a second pass, best practices, their barriers, and drivers were coded into classes to simplify analysis. In this analysis only best practices pertaining to institutions and policy process were considered; those concerned just with infrastructure or technical design matters were excluded.

In a final and most critical pass through the texts, emphasis was placed on understanding rationales and supporting discourses for deploying specific practices in a particular situation and thus how notions of fit are understood by different actors. All illustrative quotes in this paper are excerpts from case study descriptions by experts. Responses to questions about reasons to apply a particular practice and observations about conditions that acted as barriers or opportunities provided most of the evidence about how stakeholders conceptualized fit. Many perspectives on fit were present. These were grouped based on similarity and after a few iterations a set of six dimensions of fit was derived and then used to guide the definition of quantitative indicators described below as well as provide a logical organization for the presentation of findings (see Table 1).

\section{River basin questionnaires}

The second dataset was based on a set of expert workshops held around the world with preparatory and follow-up activities to improve, validate, and help interpret expert judgments and values from global datasets. This consultation included inputs from more than 120 experts coming from water management agencies, policy agencies, academia, nongovernmental organizations, and the private sector. Some of the individuals involved were the same as those who prepared, at separate meetings, the best practice described above.

A standard questionnaire consisting of 98 indicators was applied to the 28 case studies used here. A substantial effort went into ensuring that different scores in the river basin questionnaire had clear definitions. The questionnaire was organized into three sections covering regime, context, and performance (D'Haeyer et al. 2011). The questions were not designed directly to measure institutional fit, but the emphasis on full characterization of the governance regime was very appropriate to this exercise. Information about social and biophysical context at the river basin level was relatively more limited and one of the constraints of using this dataset for analysis of fit in this study.

Responses to questions in the survey were mostly coded on 3or 5-point scales (ABC or ABCDE) or if based on continuous indicators converted to these scales. For analysis, A's were recoded to 1's and B's to 2's and so on. On these scales, A's imply high or better performance, expected regime features or contexts (D'Haeyer et al. 2011). A key feature of the questionnaire was providing a comments section, where experts could note differences of opinion as well as basis for scoring decisions, such as noting specific legislation or policy. Several workshops had follow-up consultations to review initial scoring. Further rounds of quality checking and followups were made for unusual responses to improve reliability.

\section{Derivation of fit measures}

Based on expert views of what constitutes fit through arguments about best practices we then developed a set of possible indicators to measure fit using information contained in the questionnaire. Fit measures $\left(\mathrm{F}_{\mathrm{p}}\right)$ were defined as the ratio of institutional capacity $\left(\mathrm{I}_{\mathrm{p}}\right)$ and level of challenge from socialecological conditions $\left(\mathrm{C}_{\mathrm{p}}\right)$, adjusted so values varied between $0-1$ :

$\mathrm{F}_{\mathrm{p}}=\mathrm{I}_{\mathrm{p}} /\left(\mathrm{C}_{\mathrm{p}}+1\right)$ 
With this conceptualization, fit is lowest when institutional capacity is low, but conditions are high or most challenging; fit is highest when institutional capacity is high and conditions are low, that is, least challenging. Three points for interpretation should be made. First, because there is no reliable way of a priori saying how much capacity is needed for any particular condition, it is assumed that there is no such thing as excess capacity. Second, the measures are relative making comparison among basins straightforward, but comparison of values among dimensions more difficult to interpret. Third, the measures of fit describe institutional capacities not practices or their outcomes; many other factors can influence what practices are actually followed and what effects these have on outcomes or performance.

Condition measures $\left(\mathrm{C}_{\mathrm{p}}\right)$ were estimated by summing the difference between the observed score and the maximum possible score on all indicator variables divided by the maximum possible score and then taking the total and dividing by the total number of variables (n) and subtracting it from 1 or:

$\mathrm{C}_{\mathrm{p}}=1-\left(\sum\left(\max \left(\mathrm{s}_{\mathrm{p}, \mathrm{i}}\right)-\mathrm{s}_{\mathrm{p}, \mathrm{i}}\right) /\left(\max \left(\mathrm{s}_{\mathrm{p}, \mathrm{i}}\right)-1\right)\right) / \mathrm{n}$ for $\mathrm{i}=1$ to $\mathrm{n}$

A high score means challenging conditions, like high water stress or scarcity. Variables used in condition measures described ecological conditions, levels of resource, and other links between users and ecosystems.

Institutional capacity measures $\left(\mathrm{I}_{\mathrm{p}}\right)$ were calculated in a similar way to the conditions measures:

$\mathrm{I}_{\mathrm{p}}=\left(\Sigma\left(\max \left(\mathrm{s}_{\mathrm{p}, \mathrm{j}}\right)-\mathrm{s}_{\mathrm{p}, \mathrm{j}}\right) /\left(\max \left(\mathrm{s}_{\mathrm{p}, \mathrm{j}}\right)-1\right)\right) / \mathrm{m}$ for $\mathrm{j}=1$ to $\mathrm{m}$

A high value for $I_{p}$ means there is substantial institutional capacity to manage a particular set of challenging conditions. In this study individual variables were given equal weight and aggregated condition and institutional measures adjusted so both could theoretically vary between 0 and 1 . The decision not to weight variables was made for simplicity because justifying different weights would require a more complex set of assumptions and justifications that seemed beyond this preliminary and exploratory analysis.

As an illustrative example, allocation fit was defined as the difference between the capacity to manage water shortages and variables that indicate actual or emerging water scarcity. Capacity to manage water shortages, in turn, was assessed based on aggregation of seven individual variables derived from distinct questions in the survey. The institutions metric included three variables describing water pricing instruments, two on monitoring of surface and groundwater resources, and others on water use rights and tradable permits. The conditions metric included several measures of current and projected water availability per capita as well as a water stress index that takes into account both demand and supply issues, a climate variable, and whether or not groundwater use was within sustainable yields or not. Allocation fit was defined as the ratio of institutional and condition metrics as described above.

Details of all measures are given in the Table A1.1, while summaries of definitions are presented in the results section. It should be noted that the measures of fit are not perfectly independent: a few variables were used in more than one condition or institutional capacity variable because it made logical sense to do so. For example, water availability at the basin level was included, along with many other variables, in measures of water scarcity and difficulty of basin-level management. Aggregation of individual variables to derive fit measures and all statistical analyses were done using SPSS Version 16.0 software.

\section{RESULTS}

\section{Meanings of and variation in 'fit'}

Experts in the study region were consulted on best practices in water governance. Associated best practices were described as solutions to a class of related problems, as ways of improving institutional fit or policy processes. These observations were grouped into six different, but not mutually exclusive, meanings or dimensions of fit (Table 1). The quantitative indicators that were then derived for each of the fit measures drew on combinations of responses to 10-19 questions describing institutional capacity and level of challenging conditions.

These six dimensions of fit will be discussed in turn, but a few broad patterns should be noted. First, on average, basins in Europe had the highest fit scores (Table 2). Second, for some dimensions two regions could have fairly similar scores but be very different with respect to another dimension: for example, Europe and Eastern Europe/Central Asia had similar levels for basin management but diverged greatly in terms of participation.

\section{Allocation}

The first notion of fit we considered was the match between capacities to manage water shortages and scarcity of water. Rising water demand and low availability was frequently identified as an important driver of interest in and implementation of best practices related to allocation.

Most experts focused on tools like pricing and modeling to optimally allocate water under conditions of scarcity. A few emphasized the importance of stakeholder consultation processes and user monitoring.

The quantitative measure for allocation fit was based on measures of water scarcity and capacity to manage water shortages (Table A1.2). The highest fits include the Cuareim (Uruguay), Elbe (Germany), and Tisza (Hungary; Fig. 1). The lowest fits were in the Bang Pakong (Thailand), GangesBrahmaputra (Nepal), and Amurdarya (Uzbekistan). 
Table 2. Variation in fit measures for water governance regimes across geographical regions.

\begin{tabular}{|c|c|c|c|c|c|}
\hline \multirow[t]{2}{*}{ Fit measure } & \multicolumn{5}{|c|}{ Average scores in each region } \\
\hline & Latin America & Europe & Africa & $\begin{array}{c}\text { Eastern Europe and } \\
\text { Central Asia }\end{array}$ & Southeast Asia \\
\hline F1 Allocation & .42 & .53 & .38 & .37 & .27 \\
\hline F2 Integration & .27 & .50 & .50 & .35 & .36 \\
\hline F3 Conservation & .21 & .47 & .27 & .23 & .25 \\
\hline F4 Basinization & .28 & .52 & .39 & .51 & .44 \\
\hline F5 Participation & .30 & .64 & .46 & .20 & .31 \\
\hline F6 Adaptation & .32 & .56 & .46 & .30 & .30 \\
\hline
\end{tabular}

The Bang Pakong case is an interesting example in that the low level of fit has been recognized by the government and stakeholders, and efforts are underway to improve allocation fit:

The allocation system was a follow-up to two earlier studies ... this meant that a coordinating body was in place, data for modeling had been assembled, and that stakeholder consultation processes were in place ... the network is responsible for data collection and water use report. (Bang Pakong, Thailand)

A key objective of the Department of Water Resources, for instance, was to establish a permanent unit for water allocation in their regional office. This was a goal consistent with the department's mandate, but not necessarily accepted by all other stakeholders.

Levels of water scarcity were high in the Thames and Okavango, but capacities to manage water shortages were much higher in the basin in the United Kingdom than in Namibia (Fig. A1.1), and this is reflected in fit scores (Fig. 1). Under the Water Resources Act of 1991 in the United Kingdom, for example, there are provisions for issuing drought orders and permits in times of shortage. It is also possible to amend or revoke abstraction licenses. Under the revisions made under the Water Act of 2003 conditional licenses for water abstraction and impoundment may be issued. These institutional instruments are likely to be useful for adapting to future climate.

\section{Integration}

Integration becomes increasingly important as the number and complexity of water uses increases. Integration, in turn, depends on capacities to coordinate among government agencies and with other nongovernment stakeholders. IWRM was seen by experts as an important approach to dealing with multiple, competing uses of land and water. Such issues arise more frequently when water is perceived to be seasonally scarce or where uses impact on benefits received by others. Best practices were usually articulated in form of principles and broad goals for planning and rarely as specific practices:
The strategy plan aims at improving people's livelihoods significantly in sustainable manner by ensuring people's rights over water and related resources, promoting socio-economic development for the benefit of all people while maintaining the ecological balance in the Kosi River Basin. (Nepal)

The quantitative measure for integration fit included indicators for capacities for IWRM as well as horizontal and vertical coordination more broadly. The conditions part of the index was largely a measure of socioeconomic development, the assumption being that this was an indicator of the complexity of water uses and users (Table A1.2).

Scores for integration fit were unrelated to those for allocation fit (Fig. 1). Some basins had relatively high allocation fit, but low integration fit (Cuareim), whereas others had the opposite pattern (Okavango).

The highest fit observed was in the Niger (Mali), where integration capacities were moderately high but complexity of use very low (Fig. A1.2). Basins with the highest complexity of uses were mostly in Europe including the Guadiana (Spain), Elbe (Germany), Norrström (Sweden), Thames (United Kingdom), Tisza (Hungary), and Rhine (Netherlands). In all the cases, however, fit was relatively high, as capacities for IWRM were also relatively high. Bang Pakong (Thailand) and Cuareim (Uruguay) also scored highly on complexity of use but had much lower capacities for integration (Fig. A1.2) and thus lower fits (Fig. 1). Fit with respect to integration in the Ganges-Brahmaputra varied substantially among countries, being moderately high in Bhutan, but much lower in Nepal and India. All three basins in Ecuador had low fits with respect to integration (Fig. 1). Another basin with low fit was the Amudarya (Uzbekistan).

\section{Conservation}

To address problems of poor water quality and reduced flows, which degrade aquatic ecosystems, experts favored combinations of government regulations, voluntary private standards, and market-based instruments. Environmental problems such as poor water quality and degraded aquatic ecosystems were frequently identified as an important driver 
Fig. 1. Variation in six different fit measures across 28 basins.
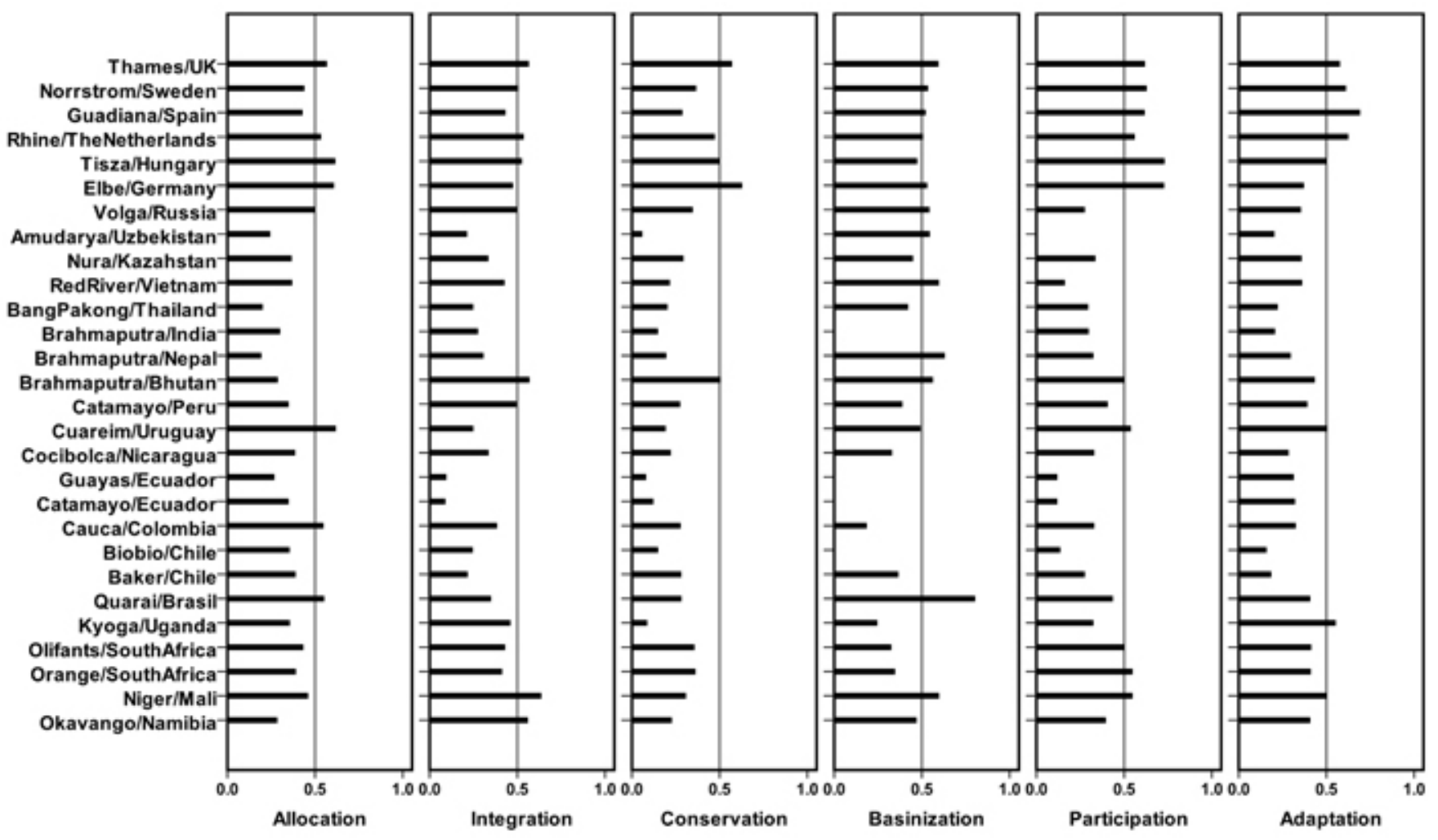

of interest in and implementation of best practices related to conservation fit.

Along the river banks of the Volga, industry is being persuaded to adopt international standards and environmental management systems. Water-user permits have been implemented. However, it is also acknowledged that overly stringent norms on water quality can be a barrier to better practices. The problem is that many water quality norms inherited from the stringent Soviet system were so high that in practice they could not be complied with by polluters and violations regularly ensued. Discussions are underway to set more realistic standards. Adoption of best practices by firms is seen as one way to improve their competitiveness. Government may help with subsidies. On the other hand if there is no financial or marketing incentive, then getting firms to reduce pollution is much harder.

Apart from examples related to pollution there were also best practice initiatives dealing with conservation of biodiversity. The Wang Watershed Management Program in Bhutan included an environmental education component that established self-sustaining nature clubs in schools and did training on monitoring rare and endangered wetland birds. The main focus of the European Commission funded program was to introduce land and farm management techniques to improve watershed management (EU 2007).

Our quantitative measure for conservation fit included measures of conditions that indicate both threat, i.e., water stress, extent of channel modification, land impacts on hydrological process, as well as impacts, i.e., aquatic biodiversity, invasive species, water quality. The institutional part reflected policy instruments, principles, as well as monitoring capacities (Table A1.2). Fit with respect to conservation falls roughly into developing versus developed country groupings (Table 2) reflecting much wider use of instruments in developed countries. However, the pattern was not strict: the Ganges-Brahmaputra (Bhutan), Elbe (Germany), Thames (UK), and Tisza (Hungary) had the highest fits (Fig. 1). Basins with relatively high threats to ecosystems included the Guadiana (Spain), Bang Pakong (Thailand), Red River (Vietnam), and Amudarya (Uzbekistan), but fit varied widely (Fig. 1) because capacities to manage ecosystems varied as well across this series (Fig. A1.3). The lowest fits included the Amudarya (Uzbekistan), Guayas (Ecuador), and Kyoga (Uganda). 


\section{Basinization}

The notion that river basins required an organization of some sort to manage them was a common claim. We have termed this dimension of fit 'basinization.' Visions and practice varied from committees that rarely meet to basin authorities with significant resources, mandate, and authority. In some places, councils and authorities both exist and were in competition with each other. Basin organizations were expected to help improve planning, water resources development, and allocation.

Basin organizations are often met with resistance or suffer from weak implementation. Inadequate attention to institutional and financial issues has been a recurrent problem in efforts to expand and transfer basin-based management practices. A common issue has been the lack of formal authority arising from the absence of appropriate water resources legislation or ambiguous laws and policies. In Thailand, for example, reforms in 2002 created a new Department of Water Resources in the Ministry of Environment and Natural Resources with mandates to implement IWRM reforms and create river basin organizations, although much of the effect of capacity and power to manage water remained with an irrigation department in another ministry (Lebel et al. 2009a). With the overarching Water Law stalled in parliament for more than a decade many steps to implement basin organizations had to be taken without formal authority making it easy for noncooperative stakeholders to block changes, but also ensuring that what progress was made was a result of negotiations (Thomas 2006). In Vietnam:

RBO structures became pawns in inter-ministerial competition: between the long established Ministry of Agriculture and Rural Development (MARD) and the newly created MONRE. MARD continued to be responsible for operation, construction and exploitation of water resources while MONRE took over most regulation and management functions though the split was not functionally perfect ... for several years each Ministry issued series of contradictory decrees and parallel structures attempting to maintain or expand authority and power. (Red River, Vietnam)

The quantitative measure of basinization fit was based on indicators of capacity to manage at basin level or the presence of basin organizations, strategies, and legislated principles and another set of indicators describing the challenges of basinlevel management that included extent of land use impacts, whether the basin was large or transboundary, and water availability issues (Table A1.2). The highest score for basinization fit was the Quarai, Brazil (Fig. 1), where there was both a high capacity but relatively mild conditions (Fig. A1.4). The Thames (United Kingdom) also had very high capacity for management at the basin level, but in much more challenging circumstances. There was very little capacity for basin level management in the Biobio (Chile), Catamayo (Ecuador), Guayas (Ecuador), and Ganges-Brahmaputra (India). For transboundary rivers, like the GangesBrahmaputra, there is another higher-level set of challenges to achieving basin-level spatial fit when dealing with developments that have transboundary impacts (Rahaman and Varis 2009).

Although experts interviewed had high hopes that basin organizations could help improve fit it is recognized that in practice there are many constraints. Creating and inserting new institutions with a better fit to hydrology, but without sufficient attention to pre-existing institutions, often creates other boundary problems (Moss 2004, Mollinga et al. 2007, Molle 2009).

\section{Participation}

Meaningful stakeholder engagement in planning and decision making was a common prescription for identifying local problems, building trust, empowering local communities, and a basis for more transparent decision making. Important drivers of public participation include histories of disadvantaged water users or vulnerable stakeholders being left out and pressures from multilateral agencies and nongovernmental organizations. At the same time it was recognized that a substantial effort may be needed in communication to let stakeholders know about the existence of plans and best practices and that involved costs:

\section{The Every River Has Its People Project (ERP) is an initiative on shared river basin management approach implemented in the Okavango River Basin in order to facilitate community participation in the Permanent Okavango Commission (OKACOM) i.e. mobilization of local aspirations into the overall river basin management ... It is necessary to know the actors of a basin, listen to their proposals, problems and ideals. This requires clarity about what to communicate. This process is slow, expensive and complex and requires huge efforts on behalf of the technical personnel, but the results contribute considerably to the achievement of development objectives. (Okavango, Namibia)}

In the Olifants basin in South Africa, water reforms since the end of White minority rule had to address historical injustices that denied sufficient access to water to many water users (van Koppen 2008). Among the new measures in transforming away from the 'white water economy' has been targeting of supplies to disadvantaged users and expanding public participation.

Context-specific modification is important for both international and domestic transfers and exchanges of good 
practices. For example, participatory water allocation in Thailand has been extended to six districts within the Bang Pakong sub-basin, and its further adaptation was required, formulating a clear concept how it can be better transferred to other basins taking into account their numerous local specifics.

Limited experience with public participation can be a barrier even when there appears to be support for such practices in water management agencies. Lack of human resources and organizational capacity to deal with new practices such as public consultation and participation are also important barriers. This includes lack of trained personnel, adequate technical knowledge and experience.

One innovative way to overcome barriers to new practices has been to decouple them from formal processes and thus give space for experimentation. In the Rhine in Germany the Wupperverband was concerned that a failure of the voluntary stakeholder process would be interpreted as a lack of management capacity so they called the process a research project.

The quantitative measure of participation fit compared capacities to engage stakeholders and the public with diversity of interests. In this case there were many appropriate indicators for the institutional capacity part of fit, but only two for diversity of interests: income inequality and the rural-urban population mix (Table A1.2). Some of the poorest fits with respect to participation were in Eastern European river basins and best fits in Europe and then Africa (Table 2); in other areas there was substantial variation within regions (Fig. 1). Low participation fit scores were also apparent in the three basins in Ecuador (Fig. 1), where capacity to engage stakeholders and public in water resources management is limited (Fig. A1.5). In the Amudarya basin in Uzbekistan, the political and cultural setting greatly constrains stakeholder participation in policy making. Efforts to introduce more adaptive forms of water management therefore had to take creative, stepwise approaches to participatory research and take care in not raising too high expectations of immediate policy influence (Hirsch et al. 2010).

\section{Adaptation}

In this paper the adaptation measure of fit covers both variability and uncertainty. Stakeholder engagement in planning was also seen as valuable for dealing with uncertainties, for example, those arising from climate change. Engagement leads to better, shared understanding of risks and thus investment needs for adaptation. It improved understanding of the uses and limits of scenarios and models and helped stakeholders explore strategies to respond to climate change such as by reducing water consumption.

Capacities to deal with variability, uncertainty, and change in water flows and qualities were widely recognized as important, and not just for the case of climate change. Most of the attention was directed at dealing with extreme events, in particular floods. In dealing with uncertainties and variability most experts focused on best practices and tools related to the management of information. Technical assistance packages are often important drivers of assessments, creation of databases, and decision support tools. Making the information user friendly was seen as a key challenge. Improved information systems were seen as helping in reducing or dealing with uncertainties.

The main purpose is to reduce weather induced hazards in term of reduced fatalities and economic losses. Increased capacity of the Department of Hydrology and Meteorology could generate a suite offlood and climate information regarding past and current climate, observable trends, future hydroclimatic projections and establish enhanced national capacity for flood risk reduction and adaptation to climate change in Nepal. The webbased real time information has the potential of providing service not only to the communities but also serving beyond border to the downstream nations - India and Bangladesh. (Nepal)

Improved institutional support for observation networks and information gathering, management, and sharing was often seen as important for supporting decisions, in the short-term for time-critical operations such as flood forecasting and response, and in longer term strategic planning such as adaptation to climate change.

In the Tisza (Hungary) the adaptive management approaches, which had been promoted and explored in informal arenas, were formally adopted in management plans of the basin (Werners et al. 2009). The New Vásárhelyi Plan for flood safety in the Hungarian part of the Tisza River Basin included six emergency flood retention reservoirs while also promoting nature conservation and environmental protection and alternative agricultural land uses in retention areas. Water managers who favor conventional practices, however, still resisted the new approaches, with the result that overall the transition to new forms of flood management may have stalled (Sendzimir et al. 2010). Well-established water bureaucracies have their own culture and norms. Thus, a key constraint in the Tisza "was the fact that many water managers favored the traditional management paradigm, which relies on massive technical infrastructure to control the Tisza River" (Tisza, Hungary). The technical, infrastructure-oriented approach to solving water management problems is widespread and often a barrier to best practices (Lebel et al. 2009b).

Institutionalizing assessment processes is seen as a good practice for dealing with uncertainties in water management. Climate change is considered a risk to successful implementation of the EU Water Framework Directive, and countries are encouraged to take climate change into account 
in developing River Basin Management Plans. The first Thames River Basin Management Plan assessed the impacts of climate change and found the basin particularly vulnerable because it is already under pressure from abstraction for public supply; during droughts as much as $80 \%$ of flow is abstracted. Flood peaks were also expected to increase. The assessment also identified win-win, no-regret, and low-regret actions.

The quantitative measure of variation fit compared capacities to manage variability and uncertainty with levels of these in climate. As for participation fit there were many appropriate indicators for institutional capacities, but only two for conditions: climate moisture variation and uncertainty of climate projections (Table A1.2). The highest scores for the variation fit measure were in Europe, with Africa intermediate and other regions, on average, relatively lower (Table 2). Highest fits were for the Rhine (Netherlands) and Guadiana (Spain) and lowest for Biobio (Chile), Baker (Chile), and Amudarya (Uzbekistan). The Elbe (Germany) had a high level of variability and uncertainty similar to the Baker (Chile) but with much greater capacity to manage that variability (Fig. A1.6).

\section{Fit profiles}

Taking into account several dimensions of fit at the same time it is possible to get an idea of the fit profile of different basins (Figs. 2, 3). A larger shaded polygon indicates overall better fit to challenging conditions than a smaller polygon. The Thames and Rhine (Fig. 2), for example, have uniformly, relatively high fits overall, whereas the Guayas or Biobio (Fig. 3 ) have relatively low overall fits. Fits in the national parts of transboundary basins can be fairly different, as illustrated by the Ganges-Brahmaputra (Fig. 2). The shape of polygons also reveals similarity in overall fit structure. Here it is apparent that several basins in countries with histories of centrally planned states have diamond shaped profiles reflecting relatively low participation and conservation fit but still substantial attention to basinization like the Volga, Red River, and most extremely the Amudarya. In Latin America, relatively low fits and absence of basin-orientation is a shared pattern of the Guayas, Catamayo, Biobio, and to lesser extent Cauca and Baker. Among the non-European countries, the Quarai (Brazil) and Niger (Mali) also have large polygons indicating relatively high fits among all dimensions (Fig. 3).

\section{DISCUSSION}

There are many perspectives on best practices that would lead to an adequate institutional fit. In this study we distilled these using the views of expert stakeholders into six dimensions and associated measures of institutional fit in river basin governance (Table 1). Together they give a sense of how well water governance regimes of particular basins are equipped to deal with a range of natural resource and user related conditions including issues like water scarcity, variability in supply, and multiple uses.
Fig. 2. Multidimensional fit profiles. Part 1.
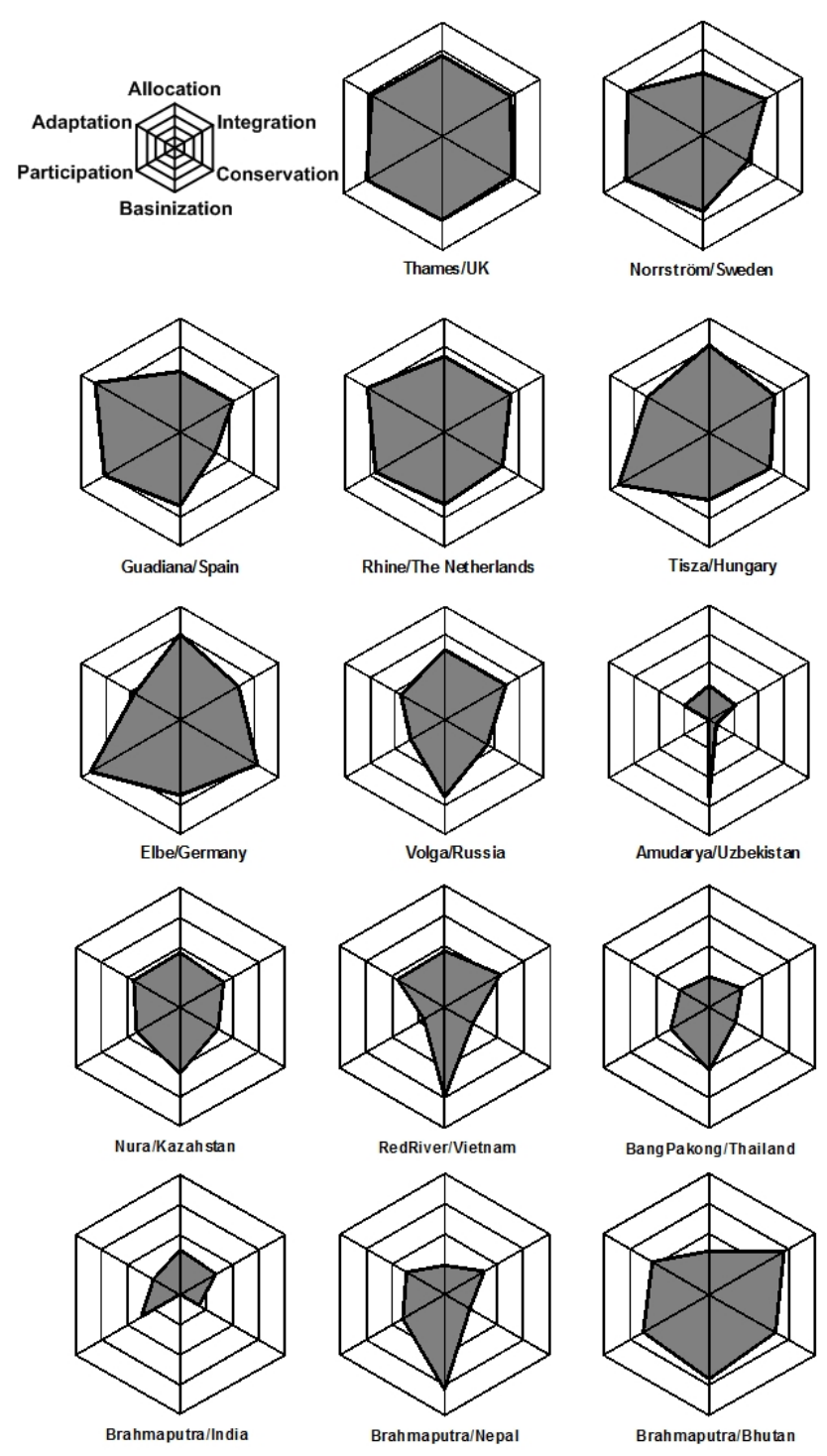

Water governance regimes of river basins varied significantly along each of the six dimensions of fit proposed and assessed in this study. Comparatively high levels of fit for at least a few measures could be found in any region of the world (Fig. 1) although on average scores were often higher in Europe than in other locations (Table 2). This suggests there are no inherent geographical barriers to achieving a high fit and that river basins in developing countries can achieve high fits. Within an individual basin, different measures of fit can diverge. This suggests it is difficult to simultaneously achieve a high fit against multiple challenging conditions. A few basins, for instance, achieve reasonably high scores on all measures of fit, whereas some score fairly lowly against most (Fig. 2). 
Fig. 3. Multidimensional fit profiles. Part 2.

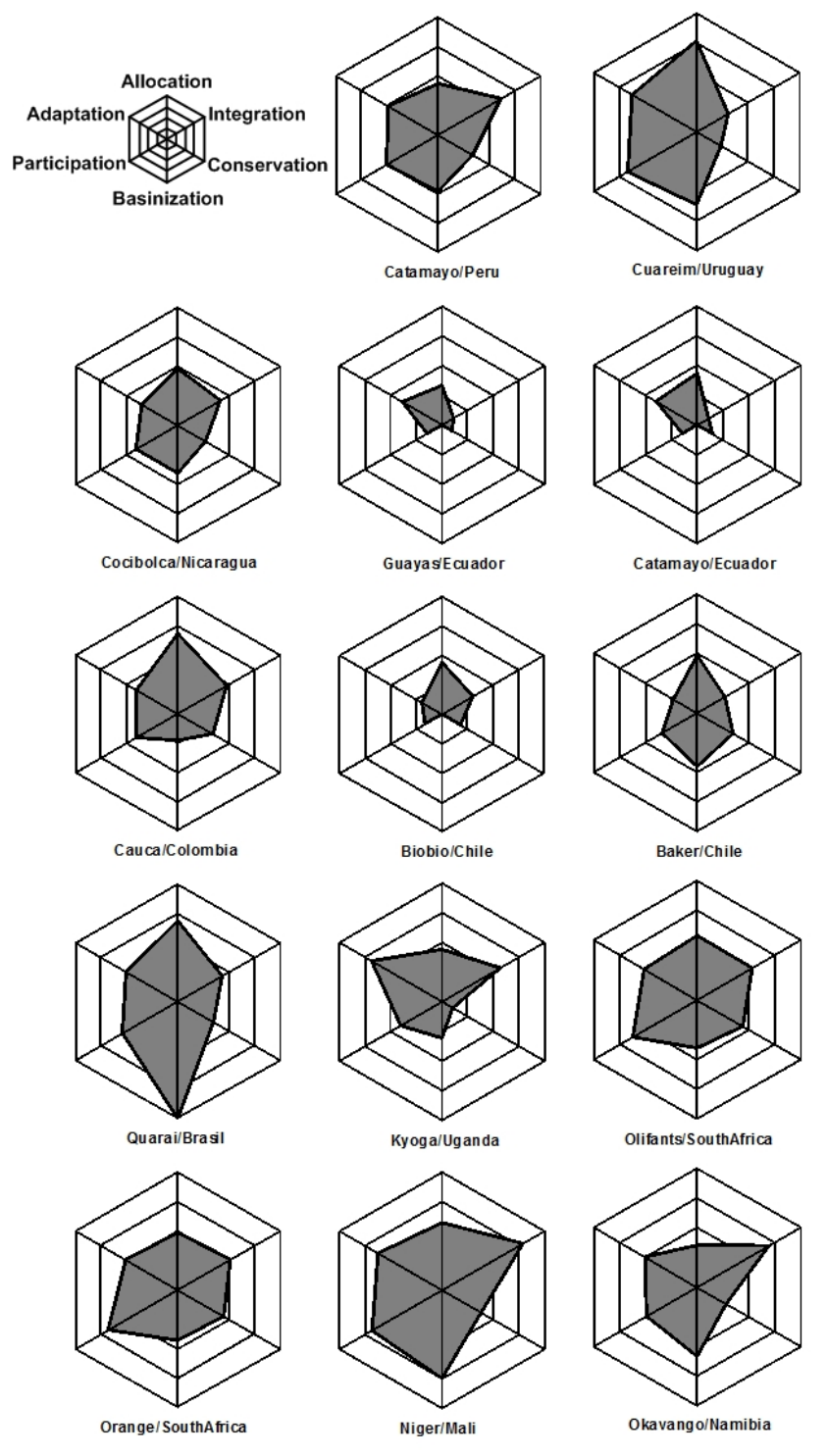

The set of measures and their analysis demonstrate the feasibility of systematically exploring fit across multiple social-ecological systems. This is a more complete characterization of the actual institutional complexity present than is often considered in comparative studies. Several distinct dimensions of fit were proposed and assessed providing a fit profile for a basin. Although individual measures have merits, limitations, and patterns of variation, a full set is also of value because it opens up possibilities of exploring trade-offs and complementarities in efforts to improve fit. The multidimensional approach to fit and use of profiles in comparative studies and diagnostic analyses deserves further exploration in systems apart from river basins.
Relative to most comparative studies of water governance the number of river basins considered was reasonably large providing a significant foundation for generalization. This foundation would be further strengthened by including information from river basins in other developed regions of the world such as North America and Australia.

Standardized fit measures may be useful for policy in at least three ways. First, they could help screen or prioritize basins for assistance or intervention. Basins with relatively low fit scores on many dimensions or unusual profiles should be targeted for additional analysis to explore reasons for the poor fit. This is likely to be most useful within countries or regions. Second, basins with high fit scores, but which other observations suggest are ineffectively governed, point to the presence of political drivers or other factors disrupting implementation. Third, monitoring changes in fit measures of a basin over time could be used to evaluate and perhaps even guide policy transitions, in particular, identifying emerging trade-offs or complementarities. Taken together these types of applications would improve the capacity to transfer better practices and successful institutional design elements across different contexts.

Our collection of expert and stakeholder views on best practices provided insights into what is thought to constitute a good fit. It is clear from many of the descriptions that rationales are still strongly influenced by the conventional predict, command and control paradigm, but that this has been disturbed by calls for greater integration, participation, transparency, and adaptiveness. Understanding and beliefs about spatial and temporal boundaries of ecosystems and key processes are amenable to management shift over time. Motivation and interests of resource users and other stakeholders also change. As the framing of both problems and solutions changes so does what is considered an adequate fit.

It is still early days in the transition between paradigms in many countries to foretell exactly how these often global discourses on good governance practices in water management (Conca 2006, Gupta 2009, Pahl-Wostl et al. 2011) will further modify notions of appropriate institutional arrangements, and how fit itself is conceived. According to experts interviewed transfers involve modification to fit social, institutional, and environmental conditions. From the perspective of recipients, the opportunities, possibilities, constraints for transfer, and needs for adaptation to local conditions vary by case.

The way we defined and measured fit in this study, as a ratio between institutional capacity and level of challenge in biophysical and social conditions, is subtly different from some other conceptualizations in the literature. Folke and colleagues (2007) emphasize fit to ecosystems without setting too much constraint on how fit might be measured. Young and others have acknowledged fit to broader 'biophysical' and 
'social' domains (Young 2002, Galaz et al. 2008). In the case of water governance biophysical characteristics of flows and stocks are critical and drive many ecosystem processes and thus threats so the broader biophysical framing is useful. To what extent and how to incorporate consideration of interconnections with users as part of definitions of fit is often left implicit. In our formulation there is no sense of "excess" fit, whereas in some other schemes such a situation is at least theoretically possible. Another area where treatments differ is whether fit refers to institutional capacities or outcomes. In our study we emphasized the former, but recognize that issues of implementation and effectiveness might also be embedded within the idea of 'fit' in some formulations. We prefer to keep questions of performance separate.

Our study had some other important limitations with respect to design and how we conceptualized and measured fit. This was a cross-sectional study. This made it possible to gather information from sufficient cases in which variation and associations could be explored across multiple river basins. However, comparisons among places do not provide a strong basis for inferring dynamics in a particular basin. Interviews of experts about best practices and improving fit provided some insights into historical processes, for example, barriers that arose and how they were overcome or not; but in-depth case research is needed to fully separate causal sequences and pathways of change as well as fully understand the full set of factors affecting transfer and adoption of best practices.

The six specific measures of fit we derived are still relatively generic because they were limited to information that we could collect in a standard format across many cases. They contain, for instance, very little ecological detail. More precise information about ecosystems would allow a much more sensitive analysis about which processes, species, and relationships are covered by an institutional arrangement or regime, and which are not (e.g., Ekstrom and Young 2009). Alternative and superior ways of defining each of the fit measures would be possible if other indicators were available. Weighting may also help refine indicators but needs to be carefully justified. More research is clearly needed on the advantages and limitations of different approaches to defining and measuring fit for comparative studies. Better ways are also needed to describe and predict the dynamics of fit.

\section{CONCLUSIONS}

The notion of fit has inspired both theoretical scholarship aimed at understanding and practical efforts aimed at improving institutional designs. This study shows the value of deriving comparable measures that capture these perceptions and relate them to place, in this case, river basins. The novel approach to measurement and comparison of fit measures helps improve understanding of context. In turn, this should help in assessing the potential of specific practices and institutional design elements to improve the effectiveness of water governance regimes in countries or places where biophysical or social conditions are unfavorable and institutional capacities are insufficient.

Responses to this article can be read online at: http://www.ecologyandsociety.org/issues/responses. php/5097

\section{Acknowledgments:}

The research leading to these results has received funding from the European Community's Seventh Framework Programme [FP7/2007-2013] under grant agreement no. 226571 for the Twin2Go project. Thanks to the following colleagues for their inputs into workshops that helped refine some of the ideas presented here: Sukontha Aekeraj, Bach Tan Sinh, Chantana Wungaeo, Annika Kramer, and Andreas Thiel. The inputs of two anonymous reviewers are also gratefully acknowledged.

\section{LITERATURE CITED}

Bryman, A. 2006. Integrating quantitative and qualitative research: how is it done? Qualitative Research 6:97-113.

Cash, D., W. N. Adger, F. Berkes, P. Garden, L. Lebel, P. Olsson, L. Pritchard, and O. R. Young. 2006. Scale and crossscale dynamics: governance and information in a multi-level world. Ecology and Society 11(2): 8. [online] URL: http:// www.ecologyandsociety.org/vol11/iss2/art8/

Chereni, A. 2007. The problem of institutional fit in integrated water resources management: a case of Zimbabwe's Mazowe catchment. Physics and Chemistry of the Earth 32:1246-1256. http://dx.doi.org/10.1016/i.pce.2007.07.024

Conca, K. 2006. Governing water: contentious transnational politics and global institution building. MIT Press, Cambridge, Massachusetts, USA.

D’Haeyer, T., C. Knieper, L. Lebel, and C. Pahl-Wostl. 2011. D.2.3 Synthesis Report. Context-sensitive comparative analysis of associations between governance properties and performance in water management. Twin2Go Project. Institute of Environmental Systems Research, University of Osnabrück, Osnabrück, Germany.

Ekstrom, J. A., and O. R. Young. 2009. Evaluating functional fit between a set of institutions and an ecosystem. Ecology and Society 14(2): 16. [online] URL: http://www.ecologyandsociety. org/vol14/iss2/art16/

European Union (EU). 2007. Bhutan: country strategy paper 2007-2013. European Union External Action Service, Brussels, Belgium. [online] URL: http://www.eeas.europa.eu/ bhutan/csp/07_13_en.pdf 
Folke, C., T. Hahn, P. Olsson, and J. Norberg. 2005. Adaptive governance of social-ecological systems. Annual Review of Environment and Resources 30:441-473. http://dx.doi. org/10.1146/annurev.energy.30.050504.144511

Folke, C., L. Pritchard, F. Berkes, J. Colding, and U. Svedin. 2007. The problem of fit between ecosystems and institutions: ten years later. Ecology and Society 12(1): 30. [online] URL: http://www.ecologyandsociety.org/vol12/iss1/art30/

Franks, T., C. Garcés-Restrepo, and F. Putuhena. 2008. Developing capacity for agricultural water management: current practice and future directions. Irrigation and Drainage 57:255-267. http://dx.doi.org/10.1002/ird.433

Galaz, V., P. Olsson, T. Hahn, and U. Svedin. 2008. The problem of fit among biophysical systems, environmental and resource regimes, and broader governance systems: insights and emerging challenges. Pages 147-186 in O. R. Young, L. A. King, and $\mathrm{H}$. Schroeder, editors. Institutions and environmental change: principal findings, applications and research frontiers. MIT Press, Cambridge, Massachusetts, USA.

Gupta, J. 2009. Driving forces in global fresh water governance. Pages 37-60 in D. Huitema and S. Meijerink, editors. Water policy entrepreneurs. A research companion to water transitions around the globe. Edward Elgar, Cheltenham, UK.

Habron, G. 2003. Role of adaptive management for watershed councils. Environmental Management 31:29-41. http://dx.doi. org/10.1007/s00267-002-2763-y

Hirsch, D., G. Abrami, R. Giordano, S. Liersch, N. Matin, and M. Schlüter. 2010. Participatory research for adaptive water management in a transition country - a case study from Uzbekistan. Ecology and Society 15(3): 23. [online] URL: http://www.ecologyandsociety.org/vol15/iss3/art23/

Huitema, D., C. Cornelisse, and B. Ottow. 2010. Is the jury still out? Toward greater insight in policy learning in participatory decision processes - the case of Dutch citizens' juries on water management in the Rhine basin. Ecology and Society 15(1): 16. [online] URL: http://www.ecologyandsociety. org/vol15/iss1/art16/

Huntjens, P., C. Pahl-Wostl, and J. Grin. 2010. Climate change adaptation in European river basins. Regional Environmental Change 10:263-284. http://dx.doi.org/10.1007/s10113-009-0108-6

Isendahl, N., A. Dewulf, M. Brugnach, G. François, S. Möllenkamp, and C. Pahl-Wostl. 2009. Assessing framing of uncertainties in water management practice. Water Resources Management 23:3191-3205. http://dx.doi.org/10.1007/ s11269-009-9429-y

Krysanova, V., C. Dickens, J. Timmerman, C. Varela-Ortega, M. Schlüter, K. Roest, P. Huntjens, F. Jaspers, H. Buiteveld,
E. Moreno, J. de Pedraza Carrera, R. Slámová, M. Martínková, I. Blanco, P. Esteve, K. Pringle, C. Pahl-Wostl, and P. Kabat. 2010. Cross-comparison of climate change adaptation strategies across large river basins in Europe, Africa and Asia. Water Resources Management 24:4121-4160. http://dx.doi. org/10.1007/s11269-010-9650-8

Lane, M. B., and C. J. Robinson. 2009. Institutional complexity and environmental management: the challenge of integration and the promise of large-scale collaboration. Australasian Journal of Environmental Management 16:16-24. http://dx.doi.org/10.1080/14486563.2009.9725213

Lankford, B., B. van Koppen, T. Franks, and H. Mahoo. 2004. Entrenched views or insufficient science? Contested causes and solutions of water allocation; insights from the Great Ruaha River Basin, Tanzania. Agricultural Water Management 69:135-153. http://dx.doi.org/10.1016/j. agwat.2004.04.005

Lebel, L., J. M. Anderies, B. Campbell, C. Folke, S. HatfieldDodds, T. P. Hughes, and J. Wilson. 2006. Governance and the capacity to manage resilience in regional social-ecological systems. Ecology and Society 11(1): 19. [online] URL: http:// www.ecologyandsociety.org/vol11/iss1/art19/

Lebel, L., P. Garden, and M. Imamura. 2005. The politics of scale, position, and place in the governance of water resources in the Mekong region. Ecology and Society 10(2): 18. [online] URL: http://www.ecologyandsociety.org/vol10/iss2/art18/

Lebel, L., P. Garden, N. Subsin, and S. N. Nan. 2009a. Averted crises, contested transitions: water management in the Upper Ping River basin, northern Thailand. Pages 137-157 in D. Huitema and S. Meijerink, editors. Water policy entrepreneurs. A research companion to water transitions around the globe. Edward Elgar, Cheltenham, UK.

Lebel, L., T. Grothmann, and B. Siebenhüner. 2010. The role of social learning in adaptiveness: insights from water management. International Environmental Agreements 10:333-353. http://dx.doi.org/10.1007/s10784-010-9142-6

Lebel, L., B. T. Sinh, P. Garden, S. Seng, L. A. Tuan, and D. V. Truc. 2009b. The promise of flood protection: dykes and dams, drains and diversions. Pages 283-306 in F. Molle, T. Foran, and J. Kakonen, editors. Contested waterscapes in the Mekong Region. Earthscan, London, UK.

Molle, F. 2009. River-basin planning and management: the social life of a concept. Geoforum 40:484-494. http://dx.doi. org/10.1016/j.geoforum.2009.03.004

Mollinga, P. P., R. S. Meinzen-Dick, and D. J. Merrey. 2007. Politics, plurality and problemsheds: a strategic approach for reform of agricultural water resources management. Development Policy Review 25:699-719. http://dx.doi. org/10.1111/j.1467-7679.2007.00393.x 
Moss, T. 2004. The governance of land use in river basins: prospects for overcoming problems of institutional interplay with the EU Water Framework Directive. Land Use Policy 21:85-94. http://dx.doi.org/10.1016/j.landusepol.2003.10.001

Myint, T. 2003. Democracy in global environmental governance: issues, interests, and actors in the Mkeong and the Rhine. Indiana Journal of Global Legal Studies 10:287-314. http://dx.doi.org/10.2979/GLS.2003.10.1.287

Nikitina, E., L. Lebel, C. Knieper, O. Smaragdova, P. Lindgaard-Jorgensen, J. Feher, and E. Sterner. 2011. D.3.3 Synthesis Report. Best practices guidelines and tools for knowledge transfer and implementation of adaptive water governance. Twin2Go Project. Institute of Environmental Systems Research, University of Osnabrück, Osnabrück, Germany.

Ostrom, E. 1990. Governing the commons. Cambridge University Press, Cambridge, UK. http://dx.doi.org/10.1017/ CBO9780511807763

Ostrom, E. 2010. Polycentric systems for coping with collective action and global environmental change. Global Environmental Change 20:550-557. http://dx.doi.org/10.1016/ j.gloenvcha.2010.07.004

Ostrom, E., M. A. Janssen, and J. M. Anderies. 2007. Going beyond panaceas. Proceedings of the National Academy of Sciences 104:15176-15178. http://dx.doi.org/10.1073/ pnas.0701886104

Pahl-Wostl, C., M. Craps, A. Dewulf, E. Mostert, D. Tabara, and T. Taillieu. 2007. Social learning and water resources management. Ecology and Society 12(2): 5. [online] URL: http://www.ecologyandsociety.org/vol12/iss2/art5/

Pahl-Wostl, C., P. Jeffrey, N. Isendahl, and M. Brugnach. 2011. Maturing the new water management paradigm: progressing from aspiration to practice. Water Resources Management 25:837-856. http://dx.doi.org/10.1007/ s11269-010-9729-2

Pahl-Wostl, C., L. Lebel, C. Knieper, and E. Nikitina. 2012. From applying panaceas to mastering complexity: toward adaptive water governance in basins. Environmental Science \& Policy 23:24-34. http://dx.doi.org/10.1016/j.envsci.2012.07.014

Rahaman, M. M., and O. Varis. 2009. Integrated water management of the Brahmaputra basin: perspectives and hope for regional development. Natural Resources Forum 33:60-75. http://dx.doi.org/10.1111/j.1477-8947.2009.01209. $\underline{x}$

Sendzimir, J., Z. Flachner, C. Pahl-Wostl, and C. Knieper. 2010. Stalled regime transition in the upper Tisza River Basin: the dynamics of linked action situations. Environmental Science \& Policy 13:604-619. http://dx.doi.org/10.1016/j. envsci.2010.09.005

Thomas, D. E. 2006. Participatory watershed management in Ping Watershed: final report. Office of Natural Resources and Environmental Policy and Planning, Ministry of Natural Resources and Environment, Bangkok, Thailand.

van Koppen, B. 2008. Redressing inequities of the past from a historical perspective: the case of the Olifants basin, South Africa. Water South Africa 34(4):432-438. [online] URL: http://www.wrc.org.za/Knowledge\%20Hub\%20Documents/Water\% 20SA\%20Journals/Manuscripts/2008/05/WaterSA 200805 Paper\% 202.pdf

Werners, S. E., Z. Flachner, P. Matczak, M. Falaleeva, and R. Leemans. 2009. Exploring earth system governance: a case study of floodplain management along the Tisza river in Hungary. Global Environmental Change-Human and Policy Dimensions 19:503-511. http://dx.doi.org/10.1016/j. gloenvcha.2009.07.003

Young, O. R. 2002. The institutional dimensions of environmental change: fit, interplay and scale. MIT Press, Cambridge, Massachusetts, USA.

Young, O. R. 2010. Institutional dynamics: resilience, vulnerability and adaptation in environmental and resource regimes. Global Environmental Change 20:378-385. http:// dx.doi.org/10.1016/j.gloenvcha.2009.10.001

Young, O. R. 2011. Land use, environmental change, and sustainable development: the role of institutional diagnostics. International Journal of the Commons 5:66-85.

Young, O. R., A. Agrawal, L. A. King, P. H. Sand, A. Underdal, and M. Wasson. 1999. Institutional dimensions of global environmental change (IDGEC). Science Plan. International Human Dimensions Programme Report No. 9. IHDP, Bonn, Germany. 
APPENDIX 1. Details of variables used to calculate fit measures and their variation among basins.

Table A1.1 River basins in dataset with codes for river basins (country) used in figures in appendix.

\begin{tabular}{ll}
\hline Code & River basin name/ country \\
\hline 1 & Biobio/Chile \\
2 & Catamayo/Peru \\
3 & Catamayo/Ecuador \\
4 & Cauca/Colombia \\
5 & Quaraí/Brazil \\
6 & Cocibolca/Nicaragua \\
7 & Baker/Chile \\
8 & Cuareim/Uruguay \\
9 & Guayas/Ecuador \\
11 & Norrström/Sweden \\
12 & Nura/Kazahstan \\
13 & Okavango/Namibia \\
14 & Thames/UK \\
15 & Kyoga/Uganda \\
16 & Niger/Mali \\
17 & BangPakong/Thailand \\
18 & Volga/Russia \\
19 & Brahmaputra/Bhutan \\
20 & Brahmaputra/India \\
21 & Brahmaputra/Nepal \\
22 & Tisza/Hungary \\
23 & Guadiana/Spain \\
24 & Elbe/Germany \\
25 & Rhine/TheNetherlands \\
26 & Amudarya/Uzbekistan \\
27 & Orange/SouthAfrica \\
28 & RedRiver/Vietnam \\
29 & Olifants/SouthAfrica \\
\hline
\end{tabular}


Table A1.2 Variables and expressions used to calculate derived fit measures. Numbers following letter ' $q$ ' refer to questions in the Twin2Go questionnaire which are briefly summarized in lists below each expression.

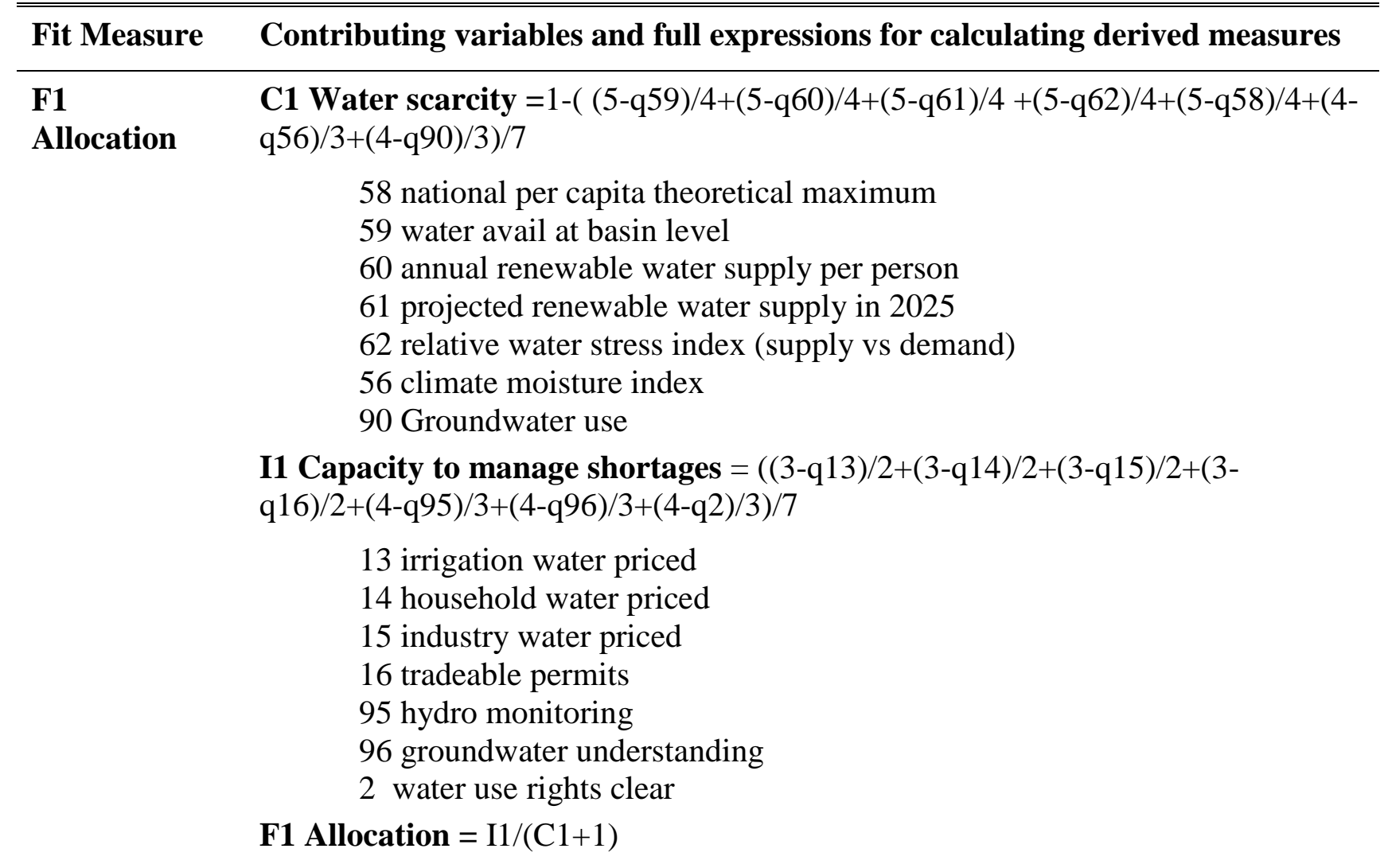

F2

Integration

C2 Complexity of uses \& users $=((4-q 43) / 3+(4-q 44) / 3+(5-q 46) / 4+(5-q 69) / 4+(5-$ $\mathrm{q} 72) / 4+(3-\mathrm{q} 67 \mathrm{aGrp}) / 2) / 6$
43 proportion in rural areas)
44 Development (HDI)
46 Per capita GDP
69 access to drinking water
72 access to sanitation
67 a basin size

I2 Capacity to integrate/coordinate uses $=((3-q 5) / 2+(3-q 24) / 2+(3-q 25) / 2+(3-$ $\mathrm{q} 26) / 2+(5-\mathrm{q} 1) / 4+(3-\mathrm{q} 6) / 2+(3-\mathrm{q} 7) / 2+(5-\mathrm{q} 34) / 4+(5-\mathrm{q} 35) / 4+(3-\mathrm{q} 36) / 2+(3-\mathrm{q} 76) / 2+(5-$ $\mathrm{q} 47) / 4+(4-\mathrm{q} 3) / 3) / 13$

5 integration of domestic water legislation

24 formalized IWRM principles

25 status of implementation

26 capacity to implement

47 Effective formal institutions (CPI)

76 Efficient \& effective

6 multilevel structure

34 vertical coordination

35 horizontal coordination 
36 role of local governments

1 domestic water law

7 administrative structure

3 law traditional uses

F2 Integration $=\mathrm{I} 2 /(\mathrm{C} 2+1)$

F3 C3 Threats to ecosystems $=1-((3-q 65) / 2+(3-q 66) / 2+(5-q 62) / 4+(4-q 87) / 3+(4-$

Conservation $\mathrm{q} 88) / 3+(4-\mathrm{q} 89) / 3) / 6$

62 Water Stress index

65 extent of flow/channel modification

66 impact of land on hydrological processes

87 Aquatic biodiversity

88 Invasives

89 Surface/groundwater quality

I3 Capacity to manage ecosystem threats $=((5-\mathrm{q} 4) / 4+(3-\mathrm{q} 17) / 2+(3-\mathrm{q} 18) / 2+(3-$ $\mathrm{q} 19) / 2+(3-\mathrm{q} 20) / 2+(3-\mathrm{q} 21) / 2+(2-\mathrm{q} 28) / 1+(3-\mathrm{q} 92) / 2+(3-\mathrm{q} 93) / 2+(3-\mathrm{q} 94) / 2) / 10$

4 flow availability/ecol requirement law

17 polluter pays

18 environmental subsidies

19 payments for ecosystem services

20 tradeable permits

28 integration of wetlands

21 environmental tax

92 water allocated for ecosystems

93 pollution incidents

94 water quality monitoring

F3 Conservation $=\mathrm{I} 3 /(\mathrm{C} 3+1)$

F4 Basin C4 Difficulty of basin-level management $=1-((5-q 60) / 4+(3-q 66) / 2+(5-$

management $q 59) / 4+(5-q 62) / 4+(\mathrm{q} 67 \mathrm{aGrp}-1) / 2+(4-q 90) / 3+(2-q 67 b) / 1) / 7$

66 land use impacts

$67 \mathrm{~b}$ transboundary $(1=\mathrm{Yes})$

67a basin size (larger is more difficult)

59 water avail at basin level

60 annual renewable water supply per person

62 relative water stress index (supply vs demand)

90 groundwater

I4 Capacity to manage at basin level $=((4-q 8) / 3+(4-q 10) / 3+(3-q 11) / 2) / 3$

8 basin organization

10 legislated basin principles

11 water basin strategies

F4 Basinization $=\mathrm{I} 4 /(\mathrm{C} 4+1)$ 
43 Population rural (intermediate fraction $=>$ more diverse interests)

I5 Capacity to engage stakeholders and public $=((5-\mathrm{q} 74) / 4+(3-\mathrm{q} 79) / 2+(3-$ $\mathrm{q} 80) / 2+(3-\mathrm{q} 50) / 2+(3-\mathrm{q} 51) / 2+(3-\mathrm{q} 75) / 2+(3-\mathrm{q} 49) / 2+(3-\mathrm{q} 77) / 2) / 8$

74 participatory decision-making practice

79 deliberative engagement opportunities

80 inclusiveness of stakeholder participation

50 participatory decision-making on books

51 transparency regarding allocation on books

75 transparent allocation in practice

49 Presence of avenues of dissent

77 equitable $\&$ inclusive

F5 Participation $=\mathrm{I} 5 /(\mathrm{C} 5+1)$

F6

Adaptation

C6 Variability and uncertainty $=1-((3-q 57) / 2+A B S(3-q 67) / 2) / 2$

57 climate moisture variation

67 uncertainty of projections (mid)

I6 Capacity to manage variability, uncertainties and change $=((3-q 29) / 2+(3-$ $\mathrm{q} 30) / 2+(3-\mathrm{q} 31) / 2+(3-\mathrm{q} 32) / 2+(3-\mathrm{q} 33) / 2+(3-\mathrm{q} 54) / 2+(4-\mathrm{q} 81) / 3+(5-\mathrm{q} 82) / 4+(3-$ $\mathrm{q} 83) / 2+(4-\mathrm{q} 84) / 3+(5-\mathrm{q} 85) / 4+(3-\mathrm{q} 86) / 2+(4-\mathrm{q} 95) / 3+(3-\mathrm{q} 94) / 2+(3-\mathrm{q} 96) / 2) / 15$

29 practices for dealing with uncertainties

30 reversible and flexible options

31 safety margins

32 use scenarios

33 climate variability $\&$ change

81 climate change strategy

82 adaptation knowledge

83 awareness of water managers

84 coordinated climate plan

85 operational activities

86 ways to deal with variability

54 IWRM \& CC predictability

94 Water quality monitoring

95 Hydro-meteorological monitoring

96 Understanding of groundwater resources

F6 Variation $=\mathrm{I} 6 /(\mathrm{C} 6+1)$ 
Figure A1.1 Variation in the condition and institutional components of the allocation fit measure across 28 basins. Darker and more solid circles indicate higher relative fit score. Numbers indicate basins as listed in Table A1.1.

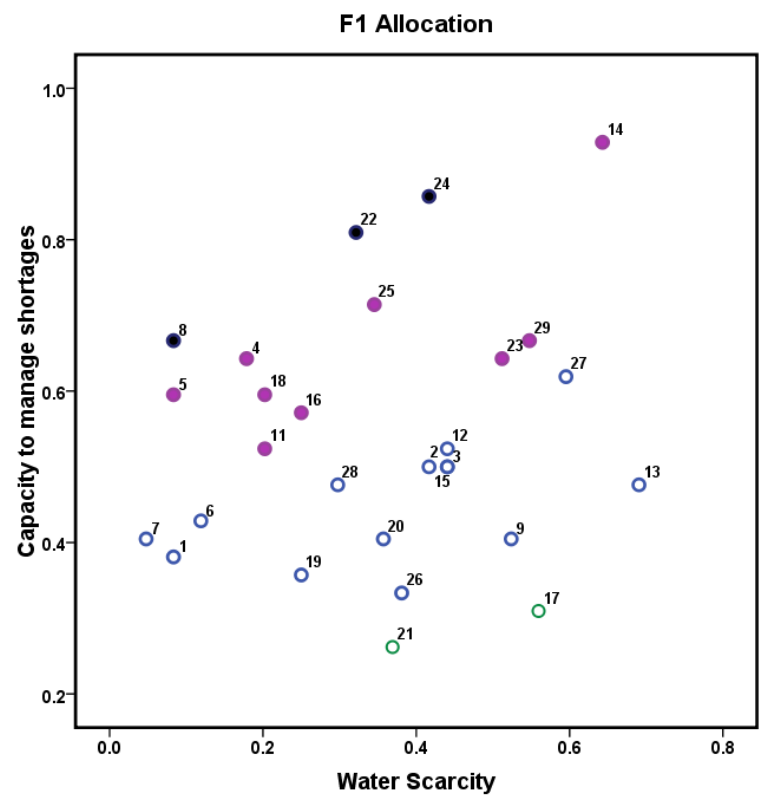

Figure A1.2 Variation in the condition and institutional components of the integration fit measure across 28 basins. Darker and more solid circles indicate higher relative fit score. Numbers indicate basins as listed in Table A1.1.

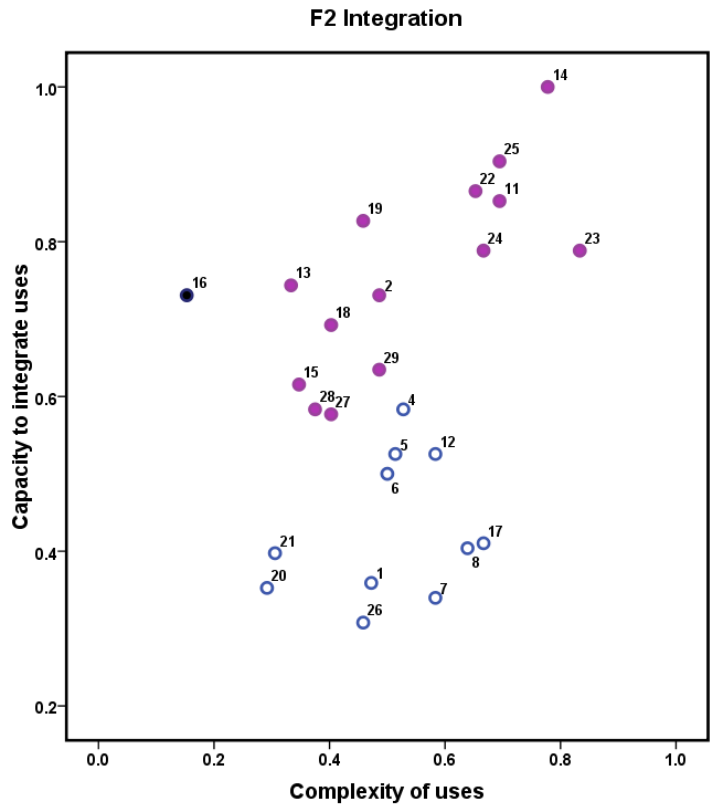


Figure A1.3 Variation in the condition and institutional components of the conservation fit measure across 28 basins. Darker and more solid circles indicate higher relative fit score. Numbers indicate basins as listed in Table A1.1.

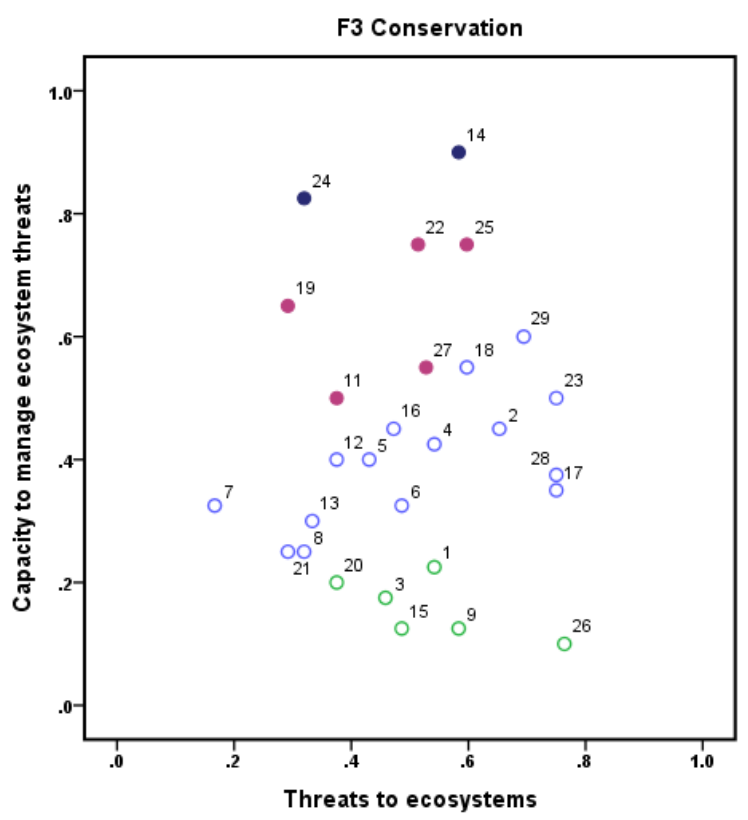

Figure A1.4 Variation in the condition and institutional components of the basinization fit measure across 28 basins. Darker and more solid circles indicate higher relative fit score. Numbers indicate basins as listed in Table A1.1.

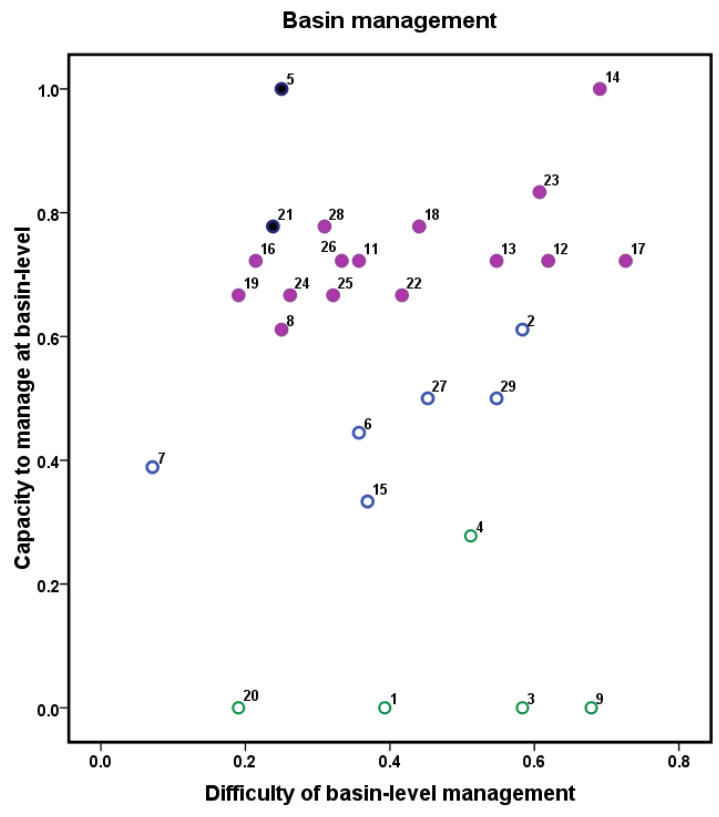


Figure A1.5 Variation in the condition and institutional components of the participation fit measure across 28 basins. Darker and more solid circles indicate higher relative fit score. Numbers indicate basins as listed in Table A1.1.

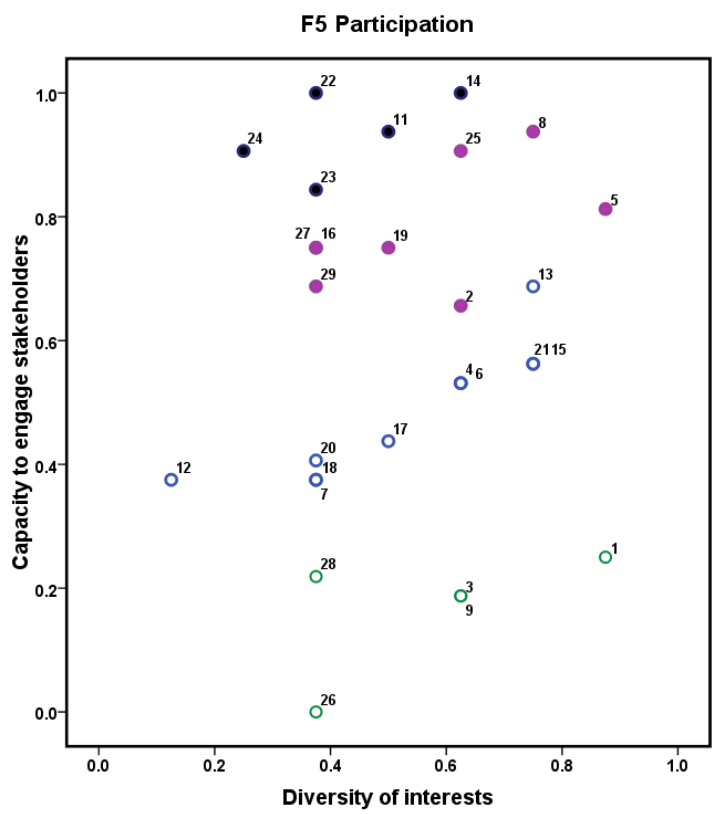

Figure A1.6 Variation in the condition and institutional components of the adaptation (or variation) fit measure across 28 basins. Darker and more solid circles indicate higher relative fit score. Numbers indicate basins as listed in Table A1.1.

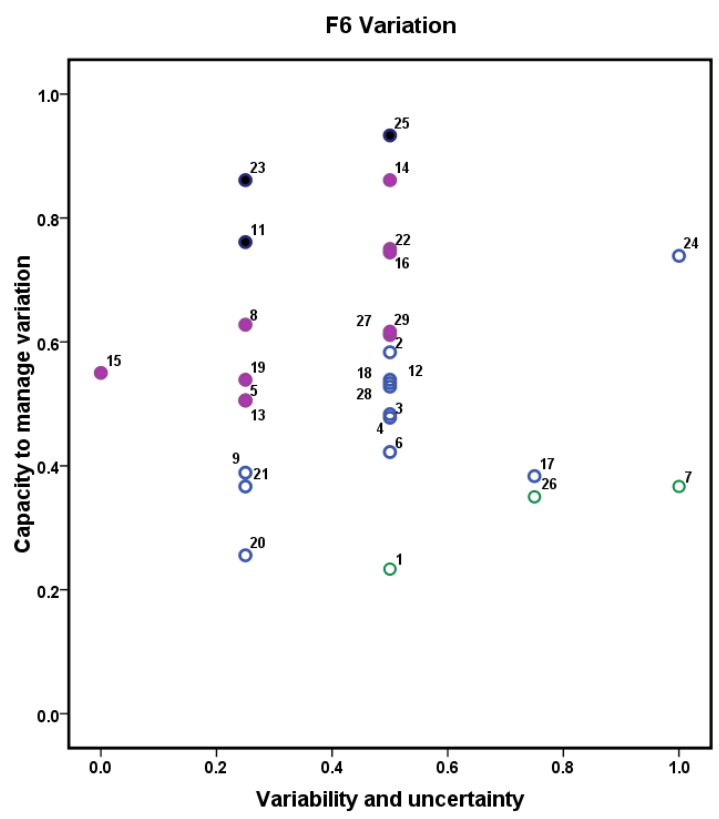

